\title{
Die funksie van die skeppingstradisie in die boek Jeremia
}

\author{
A A da Silva \\ Universiteit van Pretoria
}

\begin{abstract}
The function of the tradition of creation in Jeremiah

The purpose of this article is, firstly, to summarise Da Silva's doctoral thesis, entitled, 'The function of the tradition of creation in Jeremiah' and, secondly, to discuss the relevance of the conclusions reached in it. His examination of twelve pericopes from Jeremiah, referring to Israel's tradition of creation, results in six conclusions. The issues on which they bear relevance are theology in general, the Christian's faith, and the Christian's testimony towards non-christians and regarding the ecological movement.
\end{abstract}

\section{DOEL}

Die doel van hierdie artikel is, eerstens om 'n kort samevatting te gee van die proefskrif van Da Silva (1987:1-258), getiteld 'Die funksie van die skeppingstradisie in die boek Jeremia', en tweedens om enkele opvattings uit te spreek oor die relevansie van die gevolgtrekkings waartoe daar in die proefskrif gekom is.

\section{2. 'N KORT SAMEVATTING VAN DIE PROEFSKRIF}

\section{Israel se siening van die skeppingsgebeure}

Daar word dikwels in die boek Jeremia verwys na die skeppingsgebeure. Om te kan bepaal of Israel se siening van die skeppingsgebeure wel beskou kan word as ' $n$ 'tradisie', word al die verwysings na die skeppingsgebeure in die boek Jeremia getoets aan Fohrer (1973:99-116) se maatstawwe vir Israel se 'tradisies'. Die resultaat van hierdie ondersoek is soos volg: 
- Alle verwysings na die skeppingsgebeure in die boek Jeremia is geykte betekeniskomplekse wat handel oor die groot dade van Jahwe in die geskiedenis van sy volk.

- Al hierdie gedeeltes kan selfstandig staan.

- Daar kom ook in ander onafhanklike tekste (soos Psalms en Deutero-Jesaja) gedeeltes voor wat sterk ooreenkomste toon met die beskrywings van die skeppingsgebeure in die boek Jeremia.

- Volgens Von Rad (1957:144-146) het daar wel 'n groep bestaan wat belange gehad het by die oorlewering van die skeppingstradisies. Dit was waarskynlik die Sadokitiese priesters wat om twee redes aan Jahwe as Skepper prominensie verleen het: deels om heidense invloede tydens die ballingskap teen te werk en deels om die volk, wie se bestaansgrond met die verwoesting van die tempel onder hulle voete uitgeslaan was, weer hoop op herstel te bied.

Op grond van bogenoemde word saam met Von Rad (1957:143) aanvaar dat Israel die skeppingsgebeure gesien het as deel van hulle geskiedenis en dat hulle dit hanteer het soos al hulle ander geskiedenistradisies.

\section{Ondersoekmetode}

Om verder te kan bepaal hoe die skeppingstradisie in die boek Jeremia funksioneer, word al die perikope oor die skeppingsgebeure in Jeremia volledig geëksegetiseer. Die metode wat vir die doel gebruik word, is 'n eksegese wat uit die volgende twee fasette bestaan:

- 'n sinchroniese ondersoek, waarmee gepoog word om vas te stel wat die betekenis van die teks is, los van die lewende situasies waaruit dit kom;

- 'n diachroniese ondersoek, waarin daar gepoog word om uit te kom by die bedoeling van die teks binne die 'lewende' situasie waarin dit funksioneer.

Aan die einde van elke hoofstuk word die resultate van die eksegese onder twee hoofde opgesom. Onder die opskrif 'Semanties' word die betekenis(se) van die teks in sy huidige vorm gelys. Onder die hoof 'Semioties' word gepoog om die bedoeling van die teks binne sekere konkrete situasies saam te vat.

\subsection{Gevolgtrekkings}

Om tot finale gevolgtrekkings oor die resultate van bogenoemde eksegese te kom. word die volgende werkwyse gevolg (Da Silva 1987:239-258):

- In die eerste plek word die resultate van die eksegese op grond van hulle inhoud onder die volgende vier aspekte ingedeel: 
* die voorkoms van verwysings na die skeppingstradisie in die boek Jeremia;

* die onderskeie temas van die skeppingstradisies waarna in die boek Jeremia verwys word;

* die kombinasies wat in die boek Jeremia aangetref word tussen verwysings na die skeppingstradisie en verwysings na Israel se ander tradisies;

* die funksies van die onderskeie verwysings na die skeppingstradisie binne die konteks van die gedeeltes waarin hulle voorkom.

* Tweedens word daar, telkens ná die indeling van die eksegetiese resultate onder 'n sekere aspek, aandag gegee aan navorsers se standpunte oor sake wat verband hou met daardie spesifieke aspek.

- Derdens word daar, op grond van die vorige twee stappe se resultate, gepoog om tot geldige gevolgtrekkings te kom oor die maniere waarop en die doel waarvoor Israel se skeppingstradisie in die boek Jeremia gebruik is.

Bogenoemde resultate word kortliks onder die volgende opskrif behandel:

23.1 Eerste aspek: Die voorkoms van verwysings na die skeppingsgebeure in die boek Jeremia

2.3.1.1 Indeling van resultate onder hierdie aspek

- Dit blyk uit die eksegese van die gekose perikope dat daar in elf hoofstukke van die boek Jeremia agt en veertig keer deur middel van geykte temas en trekke verwys word na die skeppingsgebeure.

- Van hierdie agt en veertig verwysings is veertig direkte verwysings na die skeppingsgebeure en slegs agt indirekte verwysings na die skeppingsgebeure.

\subsubsection{Tersaaklike opinies en uitsprake}

- Sommige navorsers soos Duhm (1903:114) en Wright (1961:1475) beskou alle verwysings na die skeppingsgebeure in Jeremia as latere (Deuteronomistiese) toevoegings. Hulle betwyfel dus die bestaan van omskrewe opvattings oor Jahwe as Skepper in Jeremia se tyd.

- Andere soos Brongers (1945:83-86), Weiser (1966:33-37) en Von Rad (1957: 145-146), is daarvan oortuig dat daar wel in Jeremia se tyd 'n skeppingstradisie bekend was. Weippert (1981:11-14) sien gedeeltes soos Jeremia 1:5, Hosea 8:14 en Jesaja 1:2 as voor-eksiliese gedeeltes wat die verhouding tussen Jahwe en die mens beskryf as 'n verhouding tussen Skepper en skepsel. Hieruit lei sy af dat daar alreeds in Jeremia se tyd vaste oortuigings bestaan het oor Jahwe as Skepper van die wêreld. 


\subsubsection{Gevolgtrekking 1}

Op grond van die inligting vervat in 2.3.1.1 en 2.3.1.2 hierbo word daar tot die volgende gevolgtrekking gekom:

In Jeremia se tyd - en moontlik selfs vroeër - het daar alreeds ontwikkelde opvattings bestaan oor Jahwe as Skepper van die wêreld.

2.32 Tweede aspek: Temas van die skeppingstradisie waarna daar in die boek Jeremia verwys word

\subsubsection{Indeling van resultate onder hierdie aspek}

Daar word soos volg in Jeremia na die onderskeie temas van die skeppingstradisies verwys (Da Silva 1987:241-243):

- twintig keer na die sentraaltema: 'Jahwe het die hemel en die aarde geskape';

- twee en twintig keer na die deellema: 'Jahwe is Onderhouer van sy skepping';

- ses keer na verskillende newetemas.

\subsubsection{Tersaaklike opinies en uitsprake}

Weippert (1981:13) en Böhl (1978:72) wys daarop dat die werkwoord wat in Jeremia 1:5 gebruik word om Jahwe se vorming van die profeet in sy moeder se skoot te beskryf (יצר), dieselfde werkwoord is waarmee die skepping van die mens (in Gen 2:7) beskryf is. Dit, tesame met die feit dat Jahwe in Jeremia 32:27 'die God van alle mense' genoem word, dui volgens Weippert daarop dat Jahwe se skeppingshandeling telkens met die ontstaan van elke nuwe menslike lewe herhaal word. So word Jahwe se skeppingshandelinge, behalwe as afgehandelde gebeure in die veriede, ook getipeer as voortgaande optrede in die hede.

\subsubsection{Gevolgtrekking 2}

Op grond van die inligting vervat in 2.3.2.1 en 2.3.2.2 hierbo word daar tot die volgende gevolgtrekking gekom:

Daar word in Jeremia met 'Jahwe se skeppingshandelinge' twee dinge bedoel: eerstens, Jahwe se dade in die verlede toe Hy hemel en aarde geskep het; en tweedens, sy voortgesette skeppingsdade wat in die hede sigbaar is in byvoorbeeld die geboorte van mense, die wisseling van dag en nag en van seisoene, die beheer oor natuurelemente soos die see, die wind, die weerlig, en die bestuur van die lotgevalle van mense en nasies. 


\subsubsection{Derde aspek: Kombinasies met ander geskiedenistradisies}

\subsubsection{Indeling van resultate onder hierdie aspek}

- Van die elf hoofstukke in Jeremia wat verwysings na die skeppingsgebeure bevat, is daar slegs vier wat uitsluitlik na die skeppingstradisie verwys, naamlik hoofstukke 1, 3, 10 en 51 .

- Die res van die hoofstukke bevat, benewens verwysings na die skeppingstradisie, ook verwysings na een of meer van die ander geskiedenistradisies van Israel.

- Die kombinasies is soos volg:

* In vier hoofstukke (nl 4, 5, 27 \& 31) word verwysings na die skeppingstradisie gekombineer met verwysings na die Sinaïtradisie alleen;

* In een gedeelte van hoofstuk 32 word verwysings na die skeppingstradisie gekombineer met verwysings na die Sinaitradisie alleen, en in die ander gedeelte met verwysings na die eksodus-, die Sinaï- en die landinnametradisie;

-* In hoofstuk 14 word verwysings na die skeppingstradisie gekombineer met verwysings na die Dawidsverbondtradisie alleen;

* In hoofstuk 33 word verwysings na die skeppingstradisie gekombineer met verwysings na die Dawidsverbondtradisie en die aartsvadertradisie.

Kombinasies wat die meeste voorkom, is die tussen verwysings na die skeppingstradisie en verwysings na die Sinaïtradisie (nl 6 uit 12). Wat veral opvallend is, is die feit dat vyf van hierdie ses gevalle dieselfde Sitz im Leben het, naamlik dié spesifieke situasie binne die verbondsverhouding tussen Jahwe en sy volk waar Jahwe deur middel van die profeet een of ander boodskap aan die volk meedeel.

\subsubsection{Tersaaklike opinies en uitsprake}

Weippert (1981:56-59) sê op grond van bogenoemde verskynsel dat verbond en skepping in Jeremia 'saam hoort'. Volgens haar het die geloof in Jahwe as 'gegenwärtig wirkende Schöpfergott' juis op die voorgrond begin tree as gevolg van die feit dat Jahwe, wat as Verbondsgod vir sy volk ' $n$ eie land beloof het (vgl Eks 20:12; Deut $4: 1,22 ; 5: 13,16,33 ; 6: 1 ; 7: 1 ; 11: 10-17)$ daardie belofies met die inname van die land verul het.

Soortgelyke standpunte word gevind by Galling (1925:257-261), Rendtorff (1954:3-13) en Bernhardt (1960:824).

Von $\operatorname{Rad}$ (1958:146) sê ten opsigte van verwysings na die skepping: 'Wir fanden ihn durchweg in Bezogenheit, ja Abhängigkeit, von dem soteriologischen Glaubenskreis.' 


\subsubsection{Gevolgtrekkings}

Op grond van die inligting vervat in 2.3.3.1 en 2.3.3.2 hierbo word daar tot die volgende gevolgtrekkings gekom:

\section{Gevolgtrekking 3}

Die volk se geloof in Jahwe as 'n 'teenswoordige, werkende Skeppergod' het gegroei uit, en was daarom onlosmaaklik verbind aan, die volk se geloof in Jahwe as Verbondsgod.

\section{Gevolgtrekking 4}

As gevolg van die feit dat daar 'n noue verband bestaan het tussen die skeppingstradisie en die volk se geloof in Jahwe as Verbondsgod, het die skeppingstradisie nooit tot volle selfstandigheid ontwikkel nie.

2.3.4 Vierde aspek: Die funksie en die doel van die verwysings na die skeppingstradisie binne die konteks van die gedeeltes waar hulle voorkom

\subsubsection{Indeling van resultate onder hierdie aspek}

Die verskillende kontekste waarin daar in Jeremia na die skeppingstradisie verwys word, is soos volg: Sewe van die twaalf keer kom die verwysings voor in gedeeltes waar Jahwe deur die profeet met sy volk praat, twee keer waar Jahwe met die profeet alleen praat en een keer elk waar die volk met Jahwe praat, waar die profeet met Jahwe praat, en waar Jahwe 'n oordeel uitspreek oor Babel.

Wat verder van belang is, is die feit dat verwysings na die skeppingstradisie in twee groepe ingedeel kan word wat, op een uitsondering na (hfst 10), korrespondeer met die vroeë en die laat tydperk van Jeremia se optrede. So kan die verwysings in hoofstukke 1, 3, 4, 5 en 14 byvoorbeeld beskou word as verwysings uit Jeremia se vroeë tydperk (voor die ballingskap) en dié uit hoofstukke 10, 27, 31, 32 en 33 uit Jeremia se laat tydperk (net kort voor of gedurende die ballingskap).

Van eersgenoemde groep hierbo verwys hoofstukke 3, 4, 5 en 14 na Jahwe as 'Versorger' en 'Onderhouer' van die volk met wie Hy 'n verbond gesluit het. Hier word die verwysings gebruik om klem te lê op die afgryslikheid van die volk se sonde: Hulle oortreding is mér as net die verbreking van 'n paar gebooie - dit is blatante, volgehoue misbruik van die genade van die God wat hulle so getrou bly versorg! (Die enigste uitsondering by hierdie groep is hfst 1 waarin daar by implikasie na Jahwe as 'Wêreldskepper' verwys word, en waar die verwysing gebruik word om die gesag van die profeet te onderstreep: Sy woorde dra gesag omdat hy gestuur word deur dié God wat oor alles regeer.) 
Van laasgenoemde groep hierbo verwys hoofstukke 31, 32, 33, asook 51 (wat as laat-eksilies of selfs na-eksilies beskou kan word) na Jahwe as 'Werreldheerser' wat die lotgevalle van alle mense en volke beheer. Hier word die verwysings gebruik om sekere herstelbeloftes vir die ballinge te waarborg.

\subsection{Tersaaklike opinies en uitsprake}

Volz (1928:261), Von Rad (1958:147) en Weippert (1981:88) is van oordeel dat daar 'n ontwikkeling te bespeur is in Israel se beskouing van Jahwe as Skepper. Laasgenoemde druk dit soos volg uit: '[D]er Landbesitz führt zum Glauben an Jahwe als den gegenwärtig für sein Volk sorgenden Schöpfer- und Bundesgott; der drohende Landverlust zum Glauben an Jahwe als den Weltschöpfer und Herrn der Weltgeschichte."

Terwyl die land nie in gevaar was nie, was dit volgens Weippert (1981:87) vir die volk genoeg om Jahwe slegs te ken as Skepper in die sin van 'n Versorger en Onderhouer. Later, toe die land verlore was, het hulle begin vra: Het Jahwe sy volk verwerp? Het Hy beheer verloor? Sal daar ooit weer herstel kom? Hierop het Jeremia geantwoord met die geloof in Jahwe as Wêreldskepper en Heer van die wêreldgeskiedenis. 'Jahwe ist für ihn nicht mehr nur der $B a^{\prime} a l$ Palästinas, er erkennt in ihm den Ba'al der ganzen Welt' (Weippert 1981:87). Von Rad (1958:148) sien hierdie proses as 'eine wirkliche Bereicherung und Erweiterung des Heilsglaubens'.

\subsubsection{Gevolgtrekkings}

Op grond van die inligting en die opinies hierbo is die laaste twee gevolgtrekkings waartoe gekom word, die volgende:

\section{Gevolgtrekking 5}

In die vroeë tydperk van Jeremia se optrede verkondig hy Jahwe as 'n Skeppergod wat elke dag sy verbondsvolk onderhou en versorg in die land wat $\mathrm{Hy}$ aan hulle beloof het, maar wat ook van sy volk verwag om nie die verbondsvoorwaardes te verontagsaam nie.

\section{Gevolgtrekking 6}

Later, toe die volk as gevolg van hulle ongehoorsaamheid alles verloor het en begin twyfel het of Jahwe nog in staat is om hulle lot te herstel, het Jeremia Jahwe verkondig as Wêreldskepper en as Wêreldheerser. 


\section{RELEVANSIE VAN DIE PROEFSKRIF SE GEVOLGTREKKINGS}

\subsection{Relevansie vir die teologie in die algemeen}

Omdat die boek Jeremia deel is van die Christelike kanon, lewer die uitsprake oor Israel se skeppingstradisie daarin 'n groot bydrae om die kerk se teologiese opvattings oor Jahwe as Skepper van die hemel en die aarde - soos verwoord in die kerk se geloofsbelydenisse en belydenisskrifte - Bybels te verantwoord.

Die term 'Skepper' in die sin van 'Voortbrenger' van die skepping (soos dit gefunksioneer het in die vroeë gedeeltes van die boek Jeremia) behels meer as net 'n uitspraak dat Jahwe alles in die verlede 'tot stand gebring het'. Dit verkondig ook die heilsfeit dat $\mathrm{Hy}$ as voortgaande 'Onderhouer' van sy skepping nog steeds in die hede versorgend daarmee besig is en ook in die toekoms versorgend daarmee besig sal bly.

Die term 'Skepper' in die sin van 'Wêreldskepper' en 'Wêreldheerser' (soos dit gefunksioneer het in die latere gedeeltes van die boek Jeremia) verkondig Jahwe se almag oor en sy albestuur van hemel en aarde, volke en nasies, gelowige en heiden.

\subsection{Relevansie vir die Christen se geloofslewe}

Die uitsprake in die boek Jeremia dat God Skepper en Onderhouer van sy skepping is, onderstreep vir die Christen die feit dat hy vir sy ganse bestaan, van begin tot einde, afhanklik is van die krag en die genade van God.

Die verkondiging in Jeremia dat God Wêreldskepper is, hou sekere belangrike implikasies in vir die siening in die Nederduitsch Hervormde Kerk met betrekking tot die volkskerk-gedagte. As hy die evangelie aan afsonderlike volke wil bring, omdat so 'n werkwyse volgens sy oordeel die verkondiging van die evangelie ten beste sou dien binne die Godgegewe bedeling van 'n verskeidenheid van volke, is sy motief suiwer en sy optrede geregverdig. Daarenteen, as hy so 'n werkwyse wil volg bloot omdat dit vir homself sekere voordele inhou, is sy motief vals en sy optrede Bybels nie verantwoord nie.

Die verkondiging in Jeremia dat God ook Wêreldheerser is, bring vir die gelowige perspektief op die hede en hoop vir die toekoms. Al lyk dit soms of God beheer verloor het in 'n wêreld waar oorloë daagliks mense se lewens verwoes, bly dit nog steeds waar dat niks in die hede 'toevallig' gebeur nie: Jahwe is nog steeds Koning, en alles - ook die toekoms - is nog steeds aan sy raadsplan onderworpe.

\subsection{Relevansie vir die Christen se getuienis teenoor alle nie-Christene}

Die Christen kan, onder andere op grond van Jeremia se uitsprake oor Jahwe as Skepper van die ganse wêreld, aan alle nie-Christene verkondig dat Jahwe hulle geskape het en dat $\mathrm{Hy}$ 'n doel met hulle bestaan het. 
Die Christen kan verder, onder andere op grond van Jeremia se uitsprake oor Jahwe as Onderhouer van die ganse skepping, vir lede van alle nie-Christelike groeperinge die versekering gee dat hulle lewens veilig in die hande van Jahwe is.

Maar dan sal die Christen ó6k, mede as gevolg van Jeremia se getuienis oor Jahwe as Wêreldskepper ên as Wêreldheerser, elke individu en elke groep mense ernstig moet vermaan om nie Jahwe se bemoeienis met hulle te sien as 'n bewys van hulle eie of hulle groepe se 'meerderwaardigheid' bo ander mense of groepe nie. Jahwe het alle mense en alle volke geskape. En die rede waarom $\mathrm{Hy}$ van tyd tot tyd mense en volke roep om sekere take vir Hom te verrig, is slegs geleê in sy absolute vrymag om met sy skepping te maak wat $\mathrm{Hy}$ wil en nie in 'n moontlikheid dat een mens of een groep dalk beter as ander mense of ander groepe kan wees nie. In die geval van groepe wat hulleself as meerderwaardig teenoor ander mense of groepe beleef, omdat hulle hulleself as God se 'uitverkorenes' beskou, sal hulle streng vermaan moet word om nie hulle sogenaamde 'uitverkorenheid' te verabsoluteer nie. En diegene wat as gevolg van so 'n gewaande meerderwaardigheid ook nog onverdraagsaam sou optree teenoor andere, sal ernstig gewaarsku moet word teen 'n vergoddeliking van hulleself of 'n verafgoding van die groep waaraan hulle behoort.

3.4 Relevansie vir die Christen se getuienis teenoor die ondersteuners van ekologiese bewegings

Op grond van Jeremia se verkondiging van Jahwe as Wêreldskepper kan die Christen homself vereenselwig met die doelstellings van dié ekologiese bewegings wat hulleself beywer vir die bewaring van die aarde se natuurskoon en vir die verantwoordelike benutting van die aarde se natuurlike hulpbronne. Maar op presies dieselfde gronde sal die Christen nie anders kan nie as om skerp kritiek uit te spreek teen alle uiterste standpunte rakende die ekologie.

So sal die Christen byvoorbeeld aan die een kant teenoor diegene wat die klem op die geskape skepping wil plaas (Buitendag 1985:9-10) en wat daarom die natuur om die natuur se onthalwe wil verheerlik ('n mens wil byna sê: vergoddelik), moet getuig dat ' $n$ mens nie 'n afgod van die natuur mag mak nie. Die natuur is, net soos die mens, deel van God se skepping. En volgens God se skeppingsordening het die mens opdrag gekry om die skepping 'te bewerk en op te pas', om met ander woorde op so 'n wyse daarmee om te gaan dat God en nié die mens of die natuur nie, daardeur verheerlik word.

Net so sal die Christen aan die ander kant ook teenoor diegene wat die natuur as 'n onuitputlike bron van rykdom wil sien wat willens en wetens deur die mens tot sy eie voordeel gebruik of misbruik kan word, moet getuig dat die skepping aan God behoort en dat die mens nie die reg het om daarmee te mak wat hy wil nie. 


\section{Literatuurverwysings}

Bernhardt, K H 1960. Zur Bedeutung der Schöpfungsvorstellung für die Religion Israels im vorexilischer Zeit. ThLZ 85, 821-824.

Böhl, F de L 1978. Weltschöpfungsgedanken im Alt-Israel. Persica 7, 1975-1978, 69-130.

Brongers, H A 1945. De scheppingstradities bij de profeten. Amsterdam: Uitgeverij H J Paris.

Buitendag, J 1985. Skepping en ekologie: 'n Sistematiese ondersoek na die teologiese verstaan van die werklikheid. DD-proefskrif, Universiteit van Pretoria.

Da Silva, A A 1987. Die funksie van die skeppingstradisie in die boek Jeremia. DD-proefskrif, Universiteit van Pretoria.

Duhm, B 1903. Das Buch Jeremia, die poetischen und prophetischen Bucher des Alten Testaments: Ubersetzungen in dem Versmassen der Urschrift III. Tübingen: Paul Siebeck.

Fohrer, G, et al 1973. Exegese des Alten Testaments: Einführung in die Methodik. Heidelberg: Quelle \& Meyer.

Galting, K 1925. Jahwe der Weltschöpfer. Theologische Blätter 35, 275-261.

Rendtorf, R 1954. Die theologische Stellung des Schöpfungsglaubens bei DeuteroJesaja. ZThK 51, 3-13.

Volz, P 1928. Der Prophet Jeremia. Leipzig: Scholl. (KAT 10.)

Von Rad, G 1957. Theologie des Alten Testaments, I: Die Theologie der historischen Uberliefenungen Israels. Münich: Kaiser.

--- 1958. Das theologische Problem des alttestamentlichen Schöpfungsglaubens, in Gesammelte Studien zum Alten Testament, 136-147. München: Kaiser. (Theologische Bücherei 8.)

Weippert, H 1981. Schöpfer des Himmels und der Erde. Stuttgart: Verlag Katholisches Bibelwerk GmbH.

Weiser, A 1966. Einleitung in dem Alten Testament. Göttingen: Vandenhoeck.

Wright, G E 1961. s v Schöpfung II im Alten Testament. RGG. 